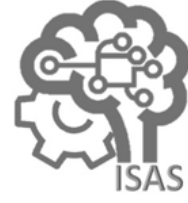

JOURNAL OF APPLIED CIVIL ENGINEERING AND INFRASTRUCTURE TECHNOLOGY (JACEIT)

Vol. 2 No. 2 (2021) 39-45

ISSN Media Elektronik: 2723-5378

\title{
Analisis Faktor Keterlambatan Pada Pembangunan Proyek X
}

\author{
Fahira Khairani ${ }^{1}$, Iwan Supriyadi ${ }^{2}$ \\ ${ }^{1}$ Jurusan Teknik Sipil, Politeknik Negeri Jakarta \\ ${ }^{2}$ Jurusan Teknik Sipil, Politeknik Negeri Jakarta \\ ${ }^{1}$ fahira.khairani.ts17@mhsw.pnj.ac.id*, ${ }^{2}$ iwan.supriyadi@pnj.ac.id
}

\begin{abstract}
In a construction project generally has its own work schedule and activities. Project planning refers to the estimates that have been generated at the time of planning. If there is a discrepancy between the planned plan and its implementation, it can cause delays in project development. Based on the s curve, in May the progress should have reached $83.8 \%$, but the realization in the field has only reached $59.2 \%$, As a result, late indications might be detected in the project. It's necessary to look at the dominant reasons of project delays based on the percentage data. The purpose of this study is to reveal or find the dominant factors that affect delays and solutions for delays in the construction of Project X. Data was collected by distributing questionnaires to individuals who were directly involved with project development such as contractors, supervisory consultants, and owners. Multiple linear regression analysis was used to analyze the data using SPSS V25 software. The financial factor with parameter $\mathrm{X}_{28}$, namely late payment by the owner obtaining a $\beta$ value of 0.386 has proven to be the most significant factor in the delay in the construction of Project $X$ and the effort to overcome this delay is to provide a letter to the owner to make a cash-in plan to pay off the outstanding payment in progress.
\end{abstract}

Keywords: Construction project, Dominant factor, Multiple linear regression, SPSS, Statistical test

\begin{abstract}
Abstrak
Dalam suatu proyek konstruksi biasanya memiliki jadwal dan kegiatan kerja tersendiri. Perencanaan proyek mengacu pada perkiraan yang telah dihasilkan pada saat pembuatan rencana. Jika terdapat perbedaan antara rencana yang telah direncanakan dengan pelaksanaannya, maka dapat menimbulkan keterlambatan pembangunan proyek. Berdasarkan kurva s, pada bulan Mei progres seharusnya sudah mencapai 83,8\%, tetapi realisasi di lapangan baru mencapai 59,2\%, maka dapat dilihat bahwa proyek memiliki indikator terlambat. Sehingga berdasarkan data persentase tersebut, perlu dilakukan kajian mengenai faktor dominan penyebab keterlambatan proyek. Tujuan dari penelitian ini ialah untuk mengungkapkan atau menemukan faktor dominan yang mempengaruhi keterlambatan serta solusi atas keterlambatan pada pembangunan Proyek X. Pengumpulan data dilakukan dengan menyebarkan kuesioner kepada individu yang terlibat langsung dengan pembangunan proyek seperti kontraktor, konsultan pengawas, dan pemilik. Analisis regresi linier berganda digunakan untuk menganalisis data dengan memakai software SPSS V25. Faktor keuangan dengan parameter $\mathrm{X}_{28}$, yaitu keterlambatan pembayaran oleh pemilik memperoleh nilai $\beta$ sebesar 0,386 terbukti menjadi faktor paling signifikan terhadap keterlambatan pembangunan Proyek X serta upaya untuk mengatasi keterlambatan tersebut ialah dengan memberikan surat kepada owner agar dibuatkan rencana cash in pelunasan outstanding pembayaran termin progres.
\end{abstract}

Kata kunci: Faktor dominan, Proyek konstruksi, Regresi linear berganda, SPSS, Uji statistik

Diterima Redaksi : 09-09-2021 | Selesai Revisi : 05-10-2021 | Diterbitkan Online : 01-12-2021 


\section{Pendahuluan}

Dalam suatu proyek konstruksi biasanya memiliki jadwal dan kegiatan kerja tersendiri yang menentukan kapan proyek harus dilaksanakan, kapan harus diselesaikan, bagaimana akan dilaksanakan, dan bagaimana sumber daya akan diberikan. Perencanaan proyek mengacu pada perkiraan yang telah dihasilkan pada saat pembuatan rencana. Jika terdapat perbedaan antara rencana yang telah direncanakan dan pelaksanaannya, maka akan menimbulkan masalah. Oleh karena itu, konsekuensi yang umum terjadi ialah keterlambatan dalam pelaksanaan proyek. [1]

Keterlambatan proyek diartikan sebagai waktu 3 . pengerjaan yang kurang digunakan sesuai dengan yang direncanakan, akibatnya satu atau lebih pekerjaan tidak selesai sesuai rencana. [2] Keterlambatan proyek dapat menimbulkan kerugian baik kepada kontraktor maupun pemilik. Bagi kontraktor, keterlambatan proyek akan menimbulkan kerugian waktu serta biaya, karena keuntungan yang telah diperhitungkan berkurang atau bahkan tidak diperoleh sama sekali. Bagi pengguna jasa, keterlambatan proyek akan menimbulkan hilangnya waktu pengerjaan hasil proyek, yang akan mengakibatkan keterlambatan penggunaan hasil pengembangan proyek. [3]

Menurut [4], Keuntungan yang diterima dan waktu penyelesaian adalah dua faktor yang dapat dipakai sebagai dasar penilaian keberhasilan sebuah proyek. Semakin cepat proyek konstruksi selesai semakin cepat bangunan tersebut dapat digunakan oleh calon pembeli atau pemilik, dan semakin cepat pula mendapatkan keterlambatan, hal tersebut dapat menjadi hambatan dalam pembangunan proyek dan disebabkan oleh berbagai aspek.

Menurut [5], melakukan penelitian sebelumnya dan diperoleh hasil bahwa aspek penyebab keterlambatan yang paling utama ialah ketenagakerjaan, dan nilai koefisien regresinya sebesar 0,807 .

Menurut [6], melakukan penelitian sebelumnya dan diperoleh hasil faktor signifikan mempengaruhi lain, keterlambatan ialah faktor lingkungan kerja, faktor keuangan dan faktor paling signifikan yaitu faktor tenaga kerja. Strategi yang dapat dilakukan ialah dengan memperkuat pengetahuan serta kemampuan para pekerja dengan mengedukasi serta memberikan pelatihan.

Berdasarkan kurva S, pada akhir Bulan Mei progres seharusnya sudah mencapai $83,8 \%$, tetapi pada realisasi di lapangan progres baru mencapai 59,2\%. Hingga bulan Mei 2021, Proyek X telah mengalami deviasi sebesar 24,6\%, sedangkan Proyek X ditargetkan progres mencapai $100 \%$ pada bulan September 2021. Sehingga berdasarkan data persentase tersebut, maka perlu dilakukan kajian mengenai faktor dominan penyebab dari keterlambatan serta solusi dari penyebab keterlambatan pada proyek X.

\section{Jenis Keterlambatan Proyek}

Menurut Kraeim dan Dickman menyatakan bahwa keterlambatan dapat diklasifikasikan menjadi 3 bentuk antara lain,

1. Keterlambatan yang dapat dikompensasikan (Compensable Delay) terjadi sebagai akibat dari perbuatan, kesalahan, atau kelalaian pemilik.

2. Keterlambatan yang tidak dapat dimaafkan (NonExcuseable Delay) terjadi sebagai akibat dari perilaku dan kecerobohan kontraktor.

Keterlambatan yang dapat dimaafkan (Excuseable Delay) terjadi sebagai akibat dari faktor-faktor di luar prediksi pemilik ataupun kontraktor. [7]

\section{Metode Penelitian}

\subsection{Rancangan Penelitian}

Penelitian ini dilakukan pada proyek x. Metode yang digunakan dalam penelitian ini adalah metode kuesioner yang terbagi menjadi 2 (dua) tahap, yaitu tahap 1 merupakan tahap memvalidasi kuesioner oleh min. 3 orang pakar yang terdiri atas 2 pakar akademisi dan 1 pakar praktisi. [8] Tahap 2 merupakan tahap penyebaran kuesioner yang telah divalidasi oleh ahli pakar kepada responden proyek. Kuesioner disebarkan kepada 33 responden yang terdiri dari kontraktor, konsultan pengawas, serta owner yang memiliki pengalaman bekerja pada Proyek X minimal selama 1 tahun atau responden mengerti mengenai permasalahan pada proyek x.

\subsection{Pengumpulan Data}

Pengumpulan data dilakukan dengan Teknik wawancara dan penyebaran kuesioner kepada responden proyek yang telah ditentukan. Kuesioner ini berisikan mengenai faktor - faktor keterlambatan serta persepsi mengenai keterlambatan proyek $\mathrm{x}$.

\subsection{Variable Penelitian}

Berikut merupakan variable dari penelitian ini antara A. Variable bebas penelitian ini yaitu, faktor-faktor keterlambatan proyek, berikut penjabaran dari faktor-faktor keterlambatan proyek.

1. Tenaga Kerja

a. Rendahnya produktivitas tenaga kerja [9]

b. Rendahnya kedisiplinan tenaga kerja [10]

c. Jumlah tim kerja yang tidak sesuai [10]

d. Rendahnya pengalaman kerja [12]

2. Bahan

a. Keterlambatan pengiriman bahan [1]

b. Kekurangan material [12]

c. Rendahnya kualitas bahan material [9]

d. Spesifikasi material kurang jelas/lengkap [9] 
3. Perencanaan dan Penjadwalan

Kembali sumber-sumber pustaka yang berkaitan

a. Kesalahan design yang dibuat oleh dengan masalah keterlambatan proyek. perencana [11]

b. Kurangnya perencanaan untuk akses dan rute material [13]

c. Tidak lengkapnya identifikasi jenis pekerjaan [11]

d. Jadwal tidak realistis [9]

4. Sistem inspeksi, Control, dan Evaluasi

a. Persetujuan izin [11]

b. Cara inspeksi oleh pemilik [1]

c. Kegagalan kontraktor melaksanakan pekerjaan [11]

5. Peralatan

a. Keterlambatan pengiriman peralatan [9]

b. Rendahnya produktivitas alat [9]

c. Kurangnya kemampuan operator dalam menggunakan alat [12]

6. Karakteristik Tempat

a. Akses ke lokasi proyek [11]

b. Tempat penyimpanan bahan/material [10]

c. Terbatasnya lahan untuk bekerja dan material [10]

7. Faktor Manajerial

a. Pengawasan proyek [10]

b. Kualitas pengontrolan pekerjaan [10]

c. Jadwal pekerjaan yang harus dikerjakan [10]

d. Komunikasi yang kurang baik antar divisi [10]

8. Faktor Keuangan

a. Keterlambatan pembayaran oleh pemilik [13]

b. Terbatasnya soal pendanaan [13]

c. Harga material yang terus meningkat [13]

9. Faktor Situasi

a. Intensitas hujan yang tinggi [1]

b. Terjadinya kecelakaan kerja [11]

c. Pemberlakuan lockdown

d. Peraturan physical distancing

e. Adanya tenaga kerja yang terkena covid19

f. Adanya staf yang terkena covid-19.

[14] [15]

B. Variable terikat penelitian ini yaitu, keterlambatan pada proyek.

\subsection{Tahapan Penelitian}

Pada penelitian ini, diawali dengan melakukan survei lokasi, lalu dapat dilanjutkan dengan mengidentifikasi serta merumuskan masalah dan menentukan tujuan serta batasan masalah pada penelitian. Berikutnya penulis melakukan studi pustaka untuk meninjau

Kemudian perlu dilakukan pengumpulan data dengan menyusun variable-variable bebas yang nantinya akan berbentuk sebuah kuesioner. Setelah data terkumpul, maka dapat dilakukan analisis menggunakan software SPSS yang hasilnya akan dibahas untuk ditarik kesimpulan mengenai faktor dominan penyebab keterlambatan dan dilanjutkan dengan pemberian solusi terhadap penyebab keterlambatan proyek $\mathrm{x}$.

Untuk lebih detailnya, proses penelitian dijelaskan pada diagram alir (Gambar 1),

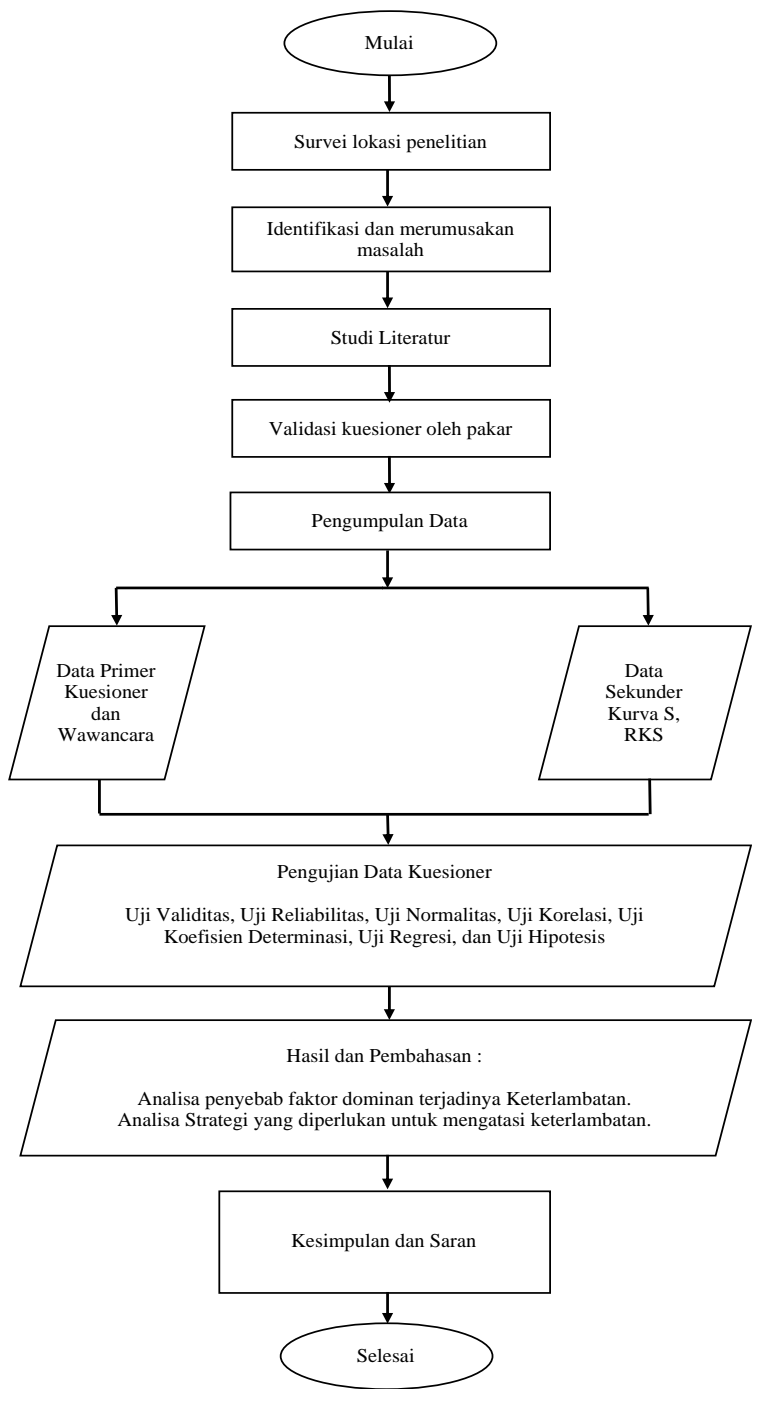

Gambar 1. Diagram Alir Penelitian

\section{Hasil dan Pembahasan}

Dari hasil rekapitulasi data yang didapat pada kuesioner tahap 2, maka selanjutnya dapat dilakukan analisis untuk menjawab permasalahan pada penelitian ini, yaitu 


\subsection{Uji Validitas}

Validitas berasal dari kata validity berarti mengacu pada suatu alat yang dipakai untuk mengukur apa yang seharusnya diukur. [8] Rumus yang dipakai dalam pengujian ini ialah Product Moment dari Pearson.

Tabel 1. Hasil Uji Validitas

\begin{tabular}{cc}
\hline Correlations & Pearson Correlation \\
\hline X1 & 0.709 \\
X2 & 0.858 \\
X3 & 0.869 \\
X4 & 0.702 \\
X5 & 0.813 \\
X6 & 0.861 \\
X7 & 0.844 \\
X8 & 0.710 \\
X9 & 0.905 \\
X10 & 0.872 \\
X11 & 0.801 \\
X12 & 0.738 \\
X13 & 0.814 \\
X14 & 0.750 \\
X15 & 0.679 \\
X16 & 0.951 \\
X17 & 0.917 \\
X18 & 0.900 \\
X19 & 0.800 \\
X20 & 0.892 \\
X21 & 0.831 \\
X22 & 0.762 \\
X23 & 0.888 \\
X24 & 0.828 \\
X25 & 0.728 \\
X26 & 0.890 \\
X27 & 0.839 \\
X28 & 0.858 \\
X29 & 0.562 \\
X30 & 0.601 \\
X31 & 0.577 \\
X32 & 0.727 \\
X33 & 0.621 \\
X34 & 0.880 \\
X35 & 0.828 \\
\hline & \\
\hline & \\
\hline & \\
\hline
\end{tabular}

Berdasarkan table diatas, hasil pengujian validasi terhadap 33 orang, diketahui bahwa nilai $r_{\text {hitung }}>r_{\text {tabel }}(r$ $=0,344)$, maka dapat diartikan bahwa seluruh indikator dalam kuesioner dikatakan valid.

\subsection{Uji Reliabilitas}

Menurut [20] "pengujian reliabilitas dapat dilaksanakan apabila butir-butir pernyataan telah valid. Pengujian ini dirancang untuk menilai suatu pernyataan dari indikator suatu variable [16]. Pada uji reliabilitas penelitian ini dilakukan dengan menggunakan analisis Cornbach Alpha.

Tabel 2. Hasil Uji Reliabilitas

\begin{tabular}{cc}
\hline Cronbach's Alpha & $\mathrm{N}$ of Items \\
\hline 0.941 & 35 \\
\hline
\end{tabular}

Berdasarkan table ditas, dapat dilihat bahwa nilai cronbach's alpha dengan 35 indikator ialah 0,941. Maka pengujian memiliki derajat reliabilitas yang sangat tinggi.

\subsection{Uji Normalitas}

Pengujian ini dilakukan guna mengevaluasi nilai residual dalam model regresi apakah terdistribusi normal.[17] Pada pengujian ini digunakan uji Shapiro Wilk. Asumsi normalitas terpenuhi apabila nilai asymp sig. > a $(0,05) \cdot[18]$

Tabel 3. Hasil Uji Normalitas

\begin{tabular}{cccc}
\hline \multicolumn{4}{c}{ Tests of Normality } \\
\cline { 2 - 5 } & Statistic & df & Sig. \\
\hline TOTAL_X & 0.952 & 33 & 0.150 \\
\hline
\end{tabular}

Berdasarkan tabel di atas, didapatkan nilai asymp sig. sebesar $0,150>0,05$. Sehingga data pada penelitian ini terdistribusi secara normal.

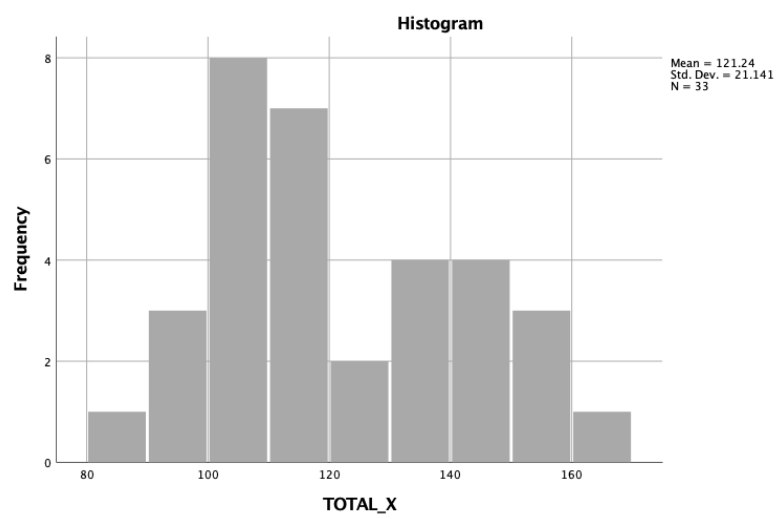

Gambar 2. Diagram Histogram Uji Normalitas

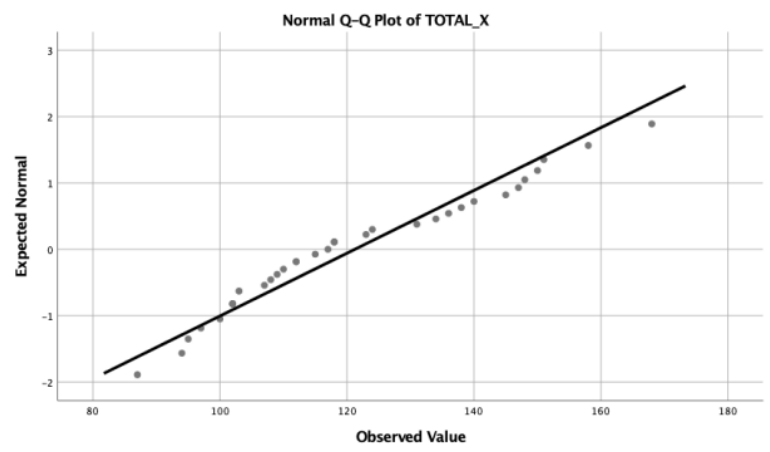

Gambar 3. Normal Q - Q Plot Uji Normalitas

\subsection{Uji Korelasi}

Pengujian ini dilakukan guna mengidentifikasi hubungan antara variable $\mathrm{x}$ dan $\mathrm{y}$. [19] Rumus yang 
dipakai dalam pengujian ini ialah korelasi Spearman's 3.5 Uji Koefisien Determinasi rho.

Tabel 4. Hasil Uji Korelasi

\begin{tabular}{|c|c|c|c|}
\hline & Correlations & & $\mathrm{Y}$ \\
\hline & TOTAL X1 & $\begin{array}{l}\text { Correlation } \\
\text { Coefficient }\end{array}$ & 0.650 \\
\hline & & Sig. (2-tailed) & 0.000 \\
\hline & & $\mathrm{N}$ & 33 \\
\hline & TOTAL X2 & $\begin{array}{l}\text { Correlation } \\
\text { Coefficient }\end{array}$ & 0.578 \\
\hline & & Sig. (2-tailed) & 0.000 \\
\hline & & $\mathrm{N}$ & 33 \\
\hline & TOTAL X3 & $\begin{array}{l}\text { Correlation } \\
\text { Coefficient }\end{array}$ & 0.459 \\
\hline & & Sig. (2-tailed) & 0.007 \\
\hline & & $\mathrm{N}$ & 33 \\
\hline & TOTAL X4 & $\begin{array}{l}\text { Correlation } \\
\text { Coefficient }\end{array}$ & 0.356 \\
\hline & & Sig. (2-tailed) & 0.042 \\
\hline & & $\mathrm{N}$ & 33 \\
\hline & TOTAL X5 & $\begin{array}{l}\text { Correlation } \\
\text { Coefficient }\end{array}$ & 0.451 \\
\hline & & Sig. (2-tailed) & 0.009 \\
\hline \multirow{16}{*}{$\begin{array}{l}\text { Spearman' } \\
\text { s rho }\end{array}$} & & $\mathrm{N}$ & 33 \\
\hline & TOTAL X6 & $\begin{array}{l}\text { Correlation } \\
\text { Coefficient }\end{array}$ & 0.464 \\
\hline & & Sig. (2-tailed) & 0.007 \\
\hline & & $\mathrm{N}$ & 33 \\
\hline & TOTAL X7 & $\begin{array}{l}\text { Correlation } \\
\text { Coefficient }\end{array}$ & 0.569 \\
\hline & & Sig. (2-tailed) & 0.001 \\
\hline & & $\mathrm{N}$ & 33 \\
\hline & TOTAL X8 & $\begin{array}{l}\text { Correlation } \\
\text { Coefficient }\end{array}$ & 0.521 \\
\hline & & Sig. (2-tailed) & 0.002 \\
\hline & & $\mathrm{N}$ & 33 \\
\hline & TOTAL X9 & $\begin{array}{l}\text { Correlation } \\
\text { Coefficient }\end{array}$ & 0.348 \\
\hline & & Sig. (2-tailed) & 0.047 \\
\hline & & $\mathrm{N}$ & 33 \\
\hline & Y & $\begin{array}{l}\text { Correlation } \\
\text { Coefficient }\end{array}$ & 1.000 \\
\hline & & Sig. (2-tailed) & $\cdot$ \\
\hline & & $\mathrm{N}$ & 33 \\
\hline
\end{tabular}

Pengujian ini dilakukan guna memeriksa apakah terdapat pengaruh variable $\mathrm{x}$ terhadap variabel $\mathrm{y}$. Pengujian ini dilakukan sebagai acuan dalam regresi $\mathrm{r}^{2}$ untuk melihat seberapa dekat garis regresi dengan nilai data asli yang dihitung oleh model.[20] Semakin besar variable $\mathrm{x}$ mempengaruhi variable $\mathrm{y}$, semakin besar pula hasil $\mathrm{r}^{2}$.

Tabel 5. Hasil Uji Koefisien Determinasi

\begin{tabular}{ccccc}
\hline \multicolumn{5}{c}{ Model Summary } \\
\hline Model & $\mathrm{R}$ & $\begin{array}{c}\mathrm{R} \\
\text { Square }\end{array}$ & $\begin{array}{c}\text { Adjusted R } \\
\text { Square }\end{array}$ & $\begin{array}{c}\text { Std. Error of } \\
\text { the Estimate }\end{array}$ \\
\hline 1 & $0.825^{\mathrm{a}}$ & 0.680 & 0.555 & 0.410 \\
\hline
\end{tabular}

Berdasarkan table di atas, didapatkan nilai adjusted $\mathrm{R}^{2}$ ialah 0,555. Sehingga dapat diartikan bahwa variable variable X mempengaruhi variable Y sebanyak 55,5\%.

\subsection{Uji Regresi Linear Berganda}

Menurut [21], "Pengujian ini dilakukan guna mengetahui apakah variable $\mathrm{X}$ dan $\mathrm{Y}$ mempunyai hubungan yang positif'.

Tabel 6. Hasil Uji Koefisien Determinasi

\begin{tabular}{|c|c|c|c|c|c|c|}
\hline & \multirow{2}{*}{ Model } & \multicolumn{2}{|c|}{$\begin{array}{c}\text { Unstandardized } \\
\text { Coefficients }\end{array}$} & \multirow{2}{*}{$\begin{array}{c}\begin{array}{c}\text { Standardized } \\
\text { Coefficients }\end{array} \\
\text { Beta }\end{array}$} & \multirow{2}{*}{$\mathrm{t}$} & \multirow{2}{*}{ Sig. } \\
\hline & & B & $\begin{array}{l}\text { Std. } \\
\text { Error }\end{array}$ & & & \\
\hline \multirow{10}{*}{1} & (Constant) & .413 & .453 & & .910 & .372 \\
\hline & TOTAL_X_1 & .101 & .037 & .533 & 2.725 & .012 \\
\hline & TOTAL_X_2 & .043 & .030 & .252 & 1.433 & .165 \\
\hline & TOTAL_X_3 & .016 & .034 & .073 & .458 & .652 \\
\hline & TOTAL_X_4 & .021 & .046 & .079 & .463 & .647 \\
\hline & TOTAL_X_5 & .084 & .035 & .462 & 2.395 & .025 \\
\hline & TOTAL_X_6 & -.043 & .048 & -.158 & -.889 & .383 \\
\hline & TOTAL_X_7 & -.070 & .045 & -.361 & -1.550 & .135 \\
\hline & TOTAL_X_8 & .133 & .040 & .593 & 3.365 & .003 \\
\hline & TOTAL_X_9 & -.046 & .021 & -.398 & -2.229 & .036 \\
\hline
\end{tabular}

Berdasarkan table diatas, berikut persamaan regresi yang didapatkan:

$$
\begin{aligned}
& Y^{\prime}=0,413+0,101 X 1+0,043 \times 2+0,016 \times 3+0,021 X 4 \\
& +0,084 X 5-0,043 X 6-0,070 X 7+0,113 \times 8-0,046 \times 9
\end{aligned}
$$

Berdasarkan tabel di atas, diketahui seluruh $r_{\text {hitung }}>r_{\text {tabel }}$ Berdasarkan persamaan regresi diatas, nilai konstanta (a) $=0,344$, maka dapat dilihat bahwa terdapat hubungan dapat diperoleh sebesar 0,413 yang artinya jika semua antara variable $\mathrm{x}$ dan $\mathrm{y}$. nilai variable $\mathrm{x}$ adalah 0 (nol), maka tingkat keterlambatan proyek ialah 0,413. Kemudian untuk variable dengan nilai positif $(+)$, artinya berpengaruh besar terhadap keterlambatan Proyek X. Variable tersebut antara lain ialah tenaga kerja, material, 
perencanaan dan penjadwalan, peralatan, sistem faktor keuangan $(3,365)$, dan faktor situasi $(2,229)$ inspeksi, control, dan evaluasi dan keuangan. merupakan faktor dominan penyebab keterlambatan Sedangkan variable dengan nilai negatif (-), artinya tidak proyek.

berpengaruh besar terhadap keterlambatan Proyek X.

Variable tersebut antara lain ialah karakteristik tempat, 3.9 Uji Dominasi manajerial, dan situasi.

\subsection{Uji F}

Penentuan variable paling dominan atau paling berpengaruh diperoleh dari koefisien beta masingmasing variable yang dapat dilihat pada uji regresi linear Pengujian ini dilakukan guna memeriksa apakah semua berganda (table 6), dapat dilihat nilai koefisien beta variable x memiliki pengaruh secara bersamaan terhadap tertinggi yaitu 0,593 ada pada variable Keuangan pada variable $y$ atau tidak melalui perbandingan antara nilai Indikator $X_{28}$. Sehingga dapat dinyatakan bahwa $\mathrm{F}_{\text {hitung }}$ dengan $\mathrm{F}_{\text {tabel }}$. [17]

Tabel 7. Hasil Uji F

\begin{tabular}{cccccc}
\hline \multicolumn{5}{c}{ ANOVA $^{\mathrm{a}}$} \\
\hline & Model & $\begin{array}{c}\text { Sum of } \\
\text { Squares }\end{array}$ & df & F & Sig. \\
\hline \multirow{4}{*}{1} & Regression & 8.202 & 9 & 5.433 & $0.000^{\mathrm{b}}$ \\
& Residual & 3.858 & 23 & & \\
& Total & 12.061 & 32 & & \\
\hline
\end{tabular}

Berdasarkan Tabel di atas, didapatkan nilai $\mathrm{F}_{\text {hitung }}=$ $5,433>\mathrm{F}_{\text {tabel }}=2,37$ dan nilai $\mathrm{Sig}=0,000<0,05$. Maka dapat dilihat bahwa Ho ditolak, Ha diterima. Sehingga Variable x mempengaruhi variable y secara bersama sama.

\section{$3.8 \mathrm{Uji} \mathrm{T}$}

Pengujian ini dilakukan guna melihat ada atau tidaknya suatu variable $\mathrm{x}$ berpengaruh secara parsial terhadap variable $y$. melalui perbandingan antara $t_{\text {hitung }}$ dengan $\mathrm{t}_{\text {tabel. }} \cdot[17]$

Tabel 8. Hasil Uji T

\begin{tabular}{cccccc}
\hline & \multicolumn{2}{c}{$\begin{array}{c}\text { Unstandardized } \\
\text { Coefficients }\end{array}$} & $\begin{array}{c}\text { Standardized } \\
\text { Coefficients }\end{array}$ & & \\
\cline { 2 - 4 } & B & $\begin{array}{c}\text { Std. } \\
\text { Erro } \\
\mathrm{r}\end{array}$ & Beta & & Sig. \\
& & & & \\
\hline (Constant) & .413 & .453 & & .910 & .372 \\
TOTAL_X_1 & .101 & .037 & .533 & 2.725 & .012 \\
TOTAL_X_2 & .043 & .030 & .252 & 1.433 & .165 \\
TOTAL_X_3 & .016 & .034 & .073 & .458 & .652 \\
TOTAL_X_4 & .021 & .046 & .079 & .463 & .647 \\
TOTAL_X_5 & .084 & .035 & .462 & 2.395 & .025 \\
\hline TOTAL_X_6 & -.043 & .048 & -.158 & -.889 & .383 \\
TOTAL_X_7 & -.070 & .045 & -.361 & - & .135 \\
TOTAL_X_8 & .133 & .040 & .593 & 3.365 & .003 \\
TOTAL_X_9 & -.046 & .021 & -.398 & - & .036 \\
\hline
\end{tabular}

Berdasarkan Tabel diatas, didapatkan nilai $\mathrm{T}_{\text {tabel }}=$ 2,069. Maka dapat dilihat bahwa faktor keterlambatan yang memenuhi syarat $\mathrm{T}_{\text {hitung }}>\mathrm{T}_{\text {tabel }}(2,069)$, yaitu faktor Tenaga kerja $(2,725)$, faktor peralatan $(2,395)$, indikator $\mathrm{X}_{28}$, yaitu "Keterlambatan pembayaran oleh pemilik" berpengaruh dominan terhadap keterlambatan proyek.

Dari uraian analisis diatas, dapat dibuat diagram peringkat faktor dominan keterlambatan Proyek X.

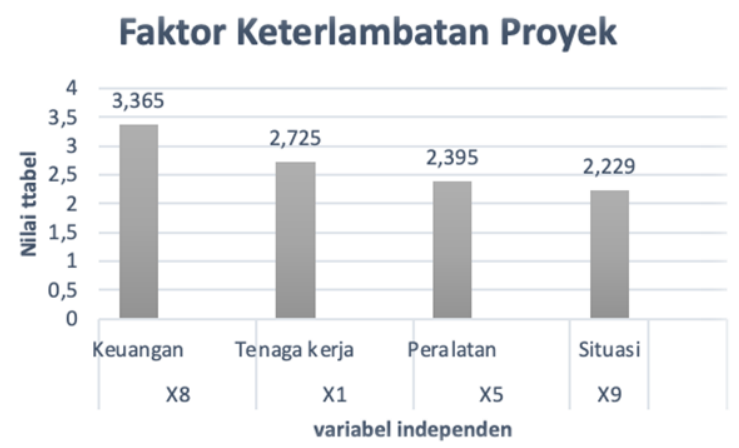

Gambar 4. Peringkat Faktor Dominan Keterlambatan Proyek X

Dilihat pada diagram diatas, diperoleh peringkat 1, 2, 3, dan 4 ialah faktor keuangan dengan $\mathrm{T}_{\text {hitung }}(3,365)$, faktor tenaga kerja dengan $\mathrm{T}_{\text {hitung }}(2,725)$, faktor peralatan dengan $\mathrm{T}_{\text {hitung }}(2,395)$ dan faktor situasi dengan $\mathrm{T}_{\text {hitung }}$ $(3,365)$ dari variabel $\mathrm{x}$ yang memiliki pengaruh signifikan terhadap variabel $\mathrm{y}$, Kemudian dicari indikator dari variable $\mathrm{x}$ yang berpengaruh paling signifikan terhadap variable y. Berikut analisis indikator dari variabel $\mathrm{x}$ yang memiliki pengaruh signifikan terhadap variable y menggunakan uji regresi dan dilihat berdasarkan hasil dari uji t :

Tabel 8. Peringkat Hasil Indikator yang Memiliki Faktor Dominan

\begin{tabular}{cccc}
\hline Faktor & Parameter & Thitung & Peringkat \\
\hline Keuangan & $\begin{array}{c}\text { Keterlambatan } \\
\text { pembayaran oleh } \\
\text { pemilik }\end{array}$ & 1,841 & 1 \\
Tenaga Kerja & $\begin{array}{c}\text { Jumlah tim kerja } \\
\text { tidak sesuai }\end{array}$ & 1,525 & 2 \\
Peralatan & $\begin{array}{c}\text { Rendahnya } \\
\text { produktivitas alat } \\
\text { Situasi }\end{array}$ & $\begin{array}{c}\text { Pemberlakuan } \\
\text { Lockdown }\end{array}$ & 2,551 \\
\hline
\end{tabular}

Journal of Applied Civil Engineering and Infrastructure (JACEIT) 


\section{Kesimpulan}

Berdasarkan hasil analisis didapatkan kesimpulan :

1. Faktor - faktor keterlambatan yang berpengaruh signifikan terhadap keterlambatan Proyek X ialah

a. Faktor Keuangan, yaitu keterlambatan pembayaran oleh pemilik.

b. Faktor Tenaga Kerja, yaitu jumlah tim kerja tidak sesuai.

c. Faktor Peralatan, yaitu rendahnya produktivitas alat.

d. Faktor Situasi, yaitu pemberlakuan lockdown.

2. Berdasarkan hasil uji dominasi, faktor paling dominan pada penelitian ini ialah faktor keuangan yang memiliki nilai $\beta$ 0,593, dengan indikator "keterlambatan pembayaran oleh pemilik".

3. Solusi dari keterlambatan tersebut ialah

a. Memberikan surat kepada owner agar dibuatkan rencana cash in pelunasan outstanding pembayaran termin progres.

b. mengajukan surat kepada owner mengenai masalah outstanding pembayaran yang telah jatuh tempo karena hal tersebut berdampak terhadap ketersediaan tenaga kerja di lapangan, sehingga nantinya dapat menyesuaikan kebutuhan manpower seperti yang telah direncanakan.

c. mengajukan surat kepada owner mengenai masalah outstanding pembayaran yang telah jatuh tempo karena hal tersebut berdampak terhadap kinerja alat di lapangan, sehingga nantinya dapat melakukan penambahan alat.

d. Melakukan evaluasi dan mengirimkan surat kepada owner agar dapat melakukan adendum kontrak karena adanya penambahan waktu serta biaya.

Berdasarkan kesimpulan yang telah diuraikan, maka saran yang dapat diberikan adalah:

1. Semua pihak yang terlibat dalam pembangunan proyek $\mathrm{x}$, perlu memperhatikan dan menindaklanjuti faktor-faktor yang menyebabkan keterlambatan agar dapat meminimalisir atau menghilangkan faktor - faktor keterlambatan tersebut dan mencari solusi terbaik agar proses pelaksanaan konstruksi dapat terlaksana dengan baik kembali.

2. Untuk penelitian selanjutnya dapat menambah jumlah proyek yang diamati, sehingga dapat membandingkan faktor keterlambatan antara satu proyek dengan yang lainnya.

\section{Daftar Rujukan}

[1] I. A. R. Widhiawati, 2009, Analisis Faktor-Faktor Penyebab
Keterlambatan Pelaksanaan Proyek Konstruksi, J. Teknol. Elektro, vol. 8, no. 2, hal. 109-114.

[2] C. Triarman dan J. Sekarsari, 2018, Analisis Faktor Penyebab Keterlambatan Waktu Pada Pekerjaan Struktur Atas Proyek Konstruksi, J. Penelit. dan Karya Ilm. Lemb. Penelit. Univ. Trisakti, vol. 3, no. 2, hal. 1-9.

[3] A. S. Ariyanto, K. A. P. Kamila, Supriyadi, M. B. Utomo, dan Wildana Latif Mahmudi, 2019, Pengaruh Keterlambatan Material Terhadap Risiko Proyek Pembangunan Gedung Parkir, Bangun Rekaprima, vol. 05, no. 2, hal. 51-58.

[4] A. Randy Putra, Miftahul Huda, T. S Rini 2018, Faktor - Faktor Yang Mempengaruhi Keterlambatan Proyek Konstruksi Di Surabaya, axial, J. Rekayasa dan Manaj. Konstr., vol. Vol 6 No.1, hal. 25-32.

[5] A. F. Romadhona dan A. T. Tenriajeng, 2020, Analisis FaktorFaktor Penyebab Keterlambatan Kerja Pada Proyek Pembangunan Gedung Bertingkat Di Indonesia, J. Proy. Tek. Sipil, vol. 3, no. 1, hal. 18-27.

[6] D. Asmaroni, 2016, Analisa Keterlambatan Waktu Pelaksanaan Proyek Pembangunan Gedung Pemerintah di Kabupaten Pamekasan, J. Rekayasa. Tek. Sipil. Univ. Madura, vol. 1, no. 1, hal. 19-23.

[7] S. Intan, W. Sapulette, dan R. C. Soukotta, 2020, Analisa Keterlambatan Waktu Pelaksanaan Proyek Konstruksi Di Kota Ambon: Klasifikasi Dan Peringkat Dari PenyebabPenyebabnya, J. Manumata, vol. 6, no. 1, hal. 19-23.

[8] Sugiyono, 2017, Metode Penelitian Kuantitatif, Kualitatif, dan $R \& D, 19$ ed. Bandung : Alfabeta.

[9] Proboyo, B. Budiman, 1999, Keterlambatan Waktu Konstruksi : Klasifikasi dan Peringkat dari Penyebab-Penyebabny, Jurnal Teknik Sipil, 1(1), 49-58.

[10] Andi, Susandi, \& Wijaya, H, 2003, on Representing Factors Influencing Time Performance of Shop-House Constructions in Surabaya, Civil Engineering Dimension, 5(1), 7-13. Retrieved from http://puslit2.petra.ac.id/ejournal/in dex.php/civ/article/view/15563.

[11] Leuhery, L, 2014, Analisis Faktor- Faktor Penyebab Terjadinya Keterlambatan Penyelesaian Pekerjaan Fisik Pada Proyek Pnpm Mandiri Di Kota Ambon, Teknik Sipil Vol., III(1), 89102.

[12] Sambasivan, Soon, Y. W, 2007, Causes and effects of delays in Malaysian construction industry, 25(5), 517-526.

[13] D. A. Langford, B. S. \& S. M. R, 2010, Organizational structures in the construction industry.

[14] Y. I. Puspitasari, J. B. Mangare, dan P. A. K. Pratasis, 2020, Analisis Faktor-Faktor Keterlambatan Pada Proyek Perumahan Casa De Viola dan Alternatif Penyelesaiannya, J. Sipil Statik, vol. 8, no. 2, hal. 141-146.

[15] B. P. Dwiputranto dan I. K. Sucita, 2020, Analisis Keterlambatan Pada Proyek Apartemen Berkonsep Transit Oriented Development (TOD), J. Poli-Teknologi, vol. 19, no. 1, hal. $63-70$

[16] S. Wiratna, 2015, SPSS untuk Penelitian, Pustaka Barus Press, Yogyakarta.

[17] Bidang Kajian Kebijakan Dan Inovasi Administrasi Negara, 2019, Processing Data Penelitian Menggunakan SPSS, Pus. Kaji. Dan Pendidik. Dan Pelatih. Apar. IV Lemb. Adm. Negara Republik Indones., vol. 53, no. 9, hal. 1-22.

[18] J. Arifin, 2017, SPSS 24 untuk Penelitian dan Skripsi. Jakarta : PT. Elex Media Komputindo.

[19] C. V. Bertan, A. K. T. Dundu, dan R. J. M. Mandagi, 2016, Pengaruh Pendayagunaan Sumber Daya Manusia (Tenaga kerja) Terhadap Hasil Pekerjaan (Studi Kasus Perumahan Taman Mapanget Raya (Tamara), J. Sipil Statik, vol. 4, no. 1, hal. $13-20$.

[20] I. Ghozali, 2015, Aplikasi Analisis dengan Multivariate dengan Program SPSS, no. 7. Semarang: Badan Penerbit Universitas Diponogoro.

[21] Sugiyono, 2015, Metode Penelitian Kombinasi (Mix Methods). Bandung: Alfabeta. 